ISSN 1980-5098@® DOI: http://dx.doi.org/10.5902/1980509833367

\title{
TÉCNICAS DE ANÁLISE DE IMAGEM PARA CARACTERIZAÇÃO DA QUALIDADE DE SEMENTES DE PARICARANA (Bowdichia virgilioides Kunth)
}

\author{
IMAGE ANALYSIS TECHNIQUES FOR THE CHARACTERIZATION OF PARICARANA (Bowdichia \\ virgilioides Kunth) SEED QUALITY
}
Juliana Maria Espíndola Lima ${ }^{1}$ Oscar José Smiderle ${ }^{2}$ João Almir Oliveira ${ }^{3}$ Maria Laene Moreira de Carvalho $^{4}$

\section{RESUMO}

A Bowdichia virgilioides Kunth., conhecida popularmente como paricarana, é uma espécie com potencial econômico paisagístico, madeireiro e para a recuperação de áreas degradadas. Objetivou-se com este trabalho a caracterização física de sementes de paricarana com diferentes cores do tegumento provenientes de 12 matrizes, utilizando técnicas de análise de imagem, além de verificar a eficiência do tratamento de superação de dormência aplicado às sementes para determinar a qualidade fisiológica. As sementes de 12 matrizes de paricarana foram classificadas em cor laranja e vermelha manualmente e com auxílio do aparelho e software Groundeye ${ }^{\circledR}$. O delineamento experimental utilizado foi inteiramente casualizado, em arranjo fatorial $12 \times 2$ (matrizes x cores) com quatro repetições. Foram avaliadas a morfometria das sementes e plântulas, raios-x, germinação, velocidade de sementes embebidas, velocidade de germinação e microscopia eletrônica de varredura das sementes. Para o teste de germinação realizou-se o tratamento de superação de dormência das sementes com água a $100^{\circ} \mathrm{C}$ por 10 segundos, e para controle de patógenos, hipoclorito de sódio a $2 \%$ por cinco minutos. As técnicas utilizadas para caracterização física das sementes de cor laranja e vermelha das 12 matrizes de paricarana são eficientes. As sementes de paricarana de cor laranja apresentam melhor qualidade física e fisiológica. $\mathrm{O}$ tratamento com água a $100^{\circ} \mathrm{C}$ por 10 segundos mais cinco minutos de imersão em hipoclorito a $2 \%$ é eficiente na superação de dormência, e controle de patógenos das sementes de cor laranja e vermelha das 12 matrizes de paricarana.

Palavras-chave: morfologia externa; coloração de tegumento; dormência; matrizes.

\begin{abstract}
The Bowdichia virgilioides Kunth, popularly known as paricarana, have economic potential for landscaping, timber, and reforestation. The objective of this work was physical characterization of paricarana seeds from 12 matrices with different seed coat coloration, using image analysis techniques, and also evaluation of

1 Bióloga, MSc., Doutoranda do Programa de Pós-Graduação em Agronomia/Fitotecnia, Universidade Federal de Lavras, Campus Universitário, Bairro Centro, CEP 37200-000, Lavras (MG), Brasil. espindolaj5@hotmail.com

2 Engenheiro Agrônomo, Dr., Pesquisador do Setor de Sementes da Embrapa Roraima, BR-174, Km 8, Bairro Distrito Industrial, CEP 69301-970, Boa Vista (RR), Brasil. oscar.smiderl@embrapa.br

3 Biólogo, Dr., Professor do Departamento de Agricultura, Universidade Federal de Lavras, Campus Universitário, Bairro Centro, CEP 37200-000, Lavras (MG), Brasil. jalmir@dag.ufla.br

4 Engenheira Agrônoma, Dra., Professora do Departamento de Agricultura, Universidade Federal de Lavras, Campus Universitário, Bairro Centro, CEP 37200-000, Lavras (MG), Brasil. mlaene@gmail.com
\end{abstract}

Recebido para publicação em 21/05/2015 e aceito em 14/06/2017

Ci. Fl., v. 28, n. 3, jul. - set., 2018 
scarification treatment efficiency to determinate the seed physiological quality. The paricarana seeds of 12 matrices were classified in two colors, orange and red, manually and with the assistance of Groundeye ${ }^{\circledR}$ hardware/software. The experimental design was completely randomized in a factorial arrangement of $12 \mathrm{x}$ 2 (matrices x colors) with four replications. The evaluations were: morphometry of the seed and seedling, $\mathrm{x}$ - rays, germination, speed of soaked seed, rate of germination and the electron microscopy seed scanning. In the germination test a scarification with water at $100^{\circ} \mathrm{C}$ for 10 seconds plus 5 minutes in hypochlorite $2 \%$ were made in the seeds to overcoming dormancy and for pathogens control. The techniques used to characterizing the physical quality of the orange and red seeds of paricarana from 12 matrices are efficient. The orange seeds of paricarana have better physical and physiological quality. Treatment with water at $100^{\circ} \mathrm{C}$ for 10 seconds plus 5 minutes immersion in hypochlorite $2 \%$ are efficient in breaking dormancy of orange and red seeds from the 12 matrices of paricarana.

Keywords: external morphology; tegument coloration; dormancy; matrices.

\section{INTRODUÇÃO}

Bowdichia virgilioides Kunth. conhecida popularmente como paricarana ou sucupira-preta, está distribuída nos Estados de Mato Grosso, Minas Gerais, Mato Grosso do Sul, Pará, Roraima e São Paulo. A árvore atinge até $16 \mathrm{~m}$ de altura, com flores bissexuadas, diclamídeas, de coloração violeta e seus frutos amadurecem entre os meses de outubro a março. As vagens são pequenas, achatadas e indeiscentes, com poucas sementes que, em geral, têm baixo porcentual de germinação. Trata-se de uma espécie com potencial econômico por possuir várias utilizações, destacando-se os potenciais paisagístico, madeireiro e recuperação de áreas degradadas (SMIDERLE; SOUSA, 2003; SILVA JÚNIOR, 2005; LORENZI, 2008).

As sementes de paricarana têm dormência tegumentar, um tipo de dormência bastante comum em espécies da família Fabaceae, e embora seja um mecanismo eficiente para garantir a sobrevivência e perpetuação da espécie, se constitui em um fator limitante à sua propagação, tendo em vista que apenas pequenas porcentagens das sementes germinam em condições naturais (LOPES et al., 1998; SMIDERLE; SCHWENGBER, 2011). No entanto, diversos métodos têm sido testados para romper a impermeabilidade do tegumento nessa espécie, como em Albuquerque et al. (2007) e Rosa-Magri e Meneghin (2014), que com o intuito de determinar o melhor método de superação de dormência dessa espécie, utilizaram tratamentos como escarificação mecânica com lixa, ácido sulfúrico, água fria e quente com diferentes temperaturas e tempos.

Dentre os trabalhos citados, o ácido sulfúrico tem sido o mais recomendado para as sementes de paricarana, no entanto, é um tratamento oneroso que produz resíduos químicos, além dos perigos envolvendo o seu manuseio. No trabalho de Smiderle e Schwengber (2011), a alternativa de fácil aplicação para que o produtor obtenha sementes de paricarana com alta germinação sem gerar resíduo ao meio ambiente é utilizar água a $100^{\circ} \mathrm{C}$ por 10 segundos para superação da dormência.

Por outro lado, estudos com ênfase na biologia das sementes de espécies florestais têm merecido atenção, por serem consideradas escassas as informações científicas que subsidiem planos de ação de manejo e conservação da diversidade biológica (BARBEDO; BILIA; FIQUEREDO-RIBEIRO, 2002). O estudo da coloração do tegumento de sementes, por exemplo, tem sido associado ao ambiente, estádio de maturação, desenvolvimento sequencial da planta-mãe e/ou herdado geneticamente (LIU et al., 2007; 
CASTELLANI; AGUIAR; PAULA, 2009), ocasionando diferença de qualidade fisiológica das sementes como foi constatado por Liu et al. (2007) Cyamopsis tetragonoloba e Flores et al. (2014) Melanoxylon brauna. Essa característica está presente nas sementes de paricarana e pode ser analisada por técnicas de análise de imagem.

O desenvolvimento de novas técnicas para avaliação da qualidade física de sementes é importante para a obtenção de lotes de sementes mais uniformes e com maior pureza física. A análise por imagens da morfologia externa da semente tem sido utilizada para classificações mais precisas de características como forma, tamanho, textura e cor da semente (VENORA et al., 2007). Este método vem sendo aplicado em alguns trabalhos utilizando espécies comerciais da família Fabaceae como em Firatligil-Durmus et al. (2010) Phaseolus vulgaris L. e Lens culinaris Medik e Igathinathane, Pordesimo e Batchelor (2009) feijão, soja, ervilha, grão-de-bico e Venora et al. (2009) Phaseolus vulgaris L. O uso dessa técnica para espécies florestais pode trazer contribuições para o manejo e produção de mudas, por proporcionar a obtenção de lotes de sementes com maior qualidade.

Além de características externas, existe a possibilidade de visualização das estruturas internas das sementes pela técnica não destrutiva de utilização do aparelho de raios-x, que permite avaliar a qualidade física das sementes, quanto à visualização de ataque de pragas, más-formações, rupturas no tegumento e sementes vazias (FORTI; CICERO; PINTO, 2010). O princípio da técnica é definido pela absorção, em diferentes quantidades e tempo de exposição dos raios-x pela semente, de acordo com suas estruturas, composição e densidade (INTERNATIONAL SEED TESTING ASSOCIATION, 2004). Em espécies florestais têm-se obtido sucesso na determinação da pureza física de sementes através deste método, como foi observado para as espécies Platypodium elegans Vog. (SOUZA et al., 2008), Eremanthus erythropappus DC. (FEITOSA et al., 2009) e Bowdichia virgilioides Kunth. (ALBURQUERQUE; GUIMARÃES, 2008).

A microscopia eletrônica é mais uma alternativa para visualização de características ultraestruturais dos tecidos vegetais (SILVA et al., 2007). O uso dessa técnica para visualização de espessura e camadas do tegumento das sementes pode ser utilizado para relacionar dormência tegumentar, e coloração de sementes associado à germinação. Mertz et al. (2009) constataram diferenças na estrutura tegumentar de sementes de soja-preta e amarela relacionadas com a permeabilidade do tegumento, ou seja, essa técnica pode trazer informações sobre a estrutura tegumentar das sementes de paricarana, pelo qual não foram encontrados trabalhos relacionados.

Dessa forma, objetivou-se avaliar a caracterização física de sementes e plântulas de paricarana com diferentes cores do tegumento provenientes de 12 matrizes, utilizando técnicas de análise de imagem, além de verificar a eficiência do tratamento de superação de dormência na qualidade fisiológica das sementes. 


\section{MATERIAL E MÉTODOS}

As vagens foram coletadas de matrizes localizadas na capital de Boa Vista e no município do Amajarí, Roraima em 2014 (Tabela 1) e, após a coleta, levadas para o Laboratório de Sementes da Embrapa Roraima, no qual foi feito o beneficiamento para a retirada das sementes, as quais foram armazenadas em sacos plásticos e enviadas ao Laboratório de Central de Sementes da Universidade Federal de Lavras para realização das avaliações da qualidade física e fisiológica.

TABELA 1: Coordenadas das matrizes de paricarana coletadas na capital de Boa Vista e no município do Amajarí, Roraima, 2014.

TABLE 1: Coordinates of paricarana matrices collected in Boa Vista and Amajarí, Roraima state, 2014.

\begin{tabular}{|c|c|c|c|}
\hline Matrizes & Local & \multicolumn{2}{|c|}{ Coordenadas } \\
\hline 1 & Boa Vista & $02^{\circ} 51^{\prime} 01,9 ’ \mathrm{~N}$ & $60^{\circ} 39^{\prime} 04,8 ’ \mathrm{~W}$ \\
\hline 2 & Amajarí & $03^{\circ} 35^{\prime} 23,5^{\prime \prime} \mathrm{N}$ & $60^{\circ} 57^{\prime} 15,9^{\prime \prime} \mathrm{W}$ \\
\hline 3 & Boa Vista & $03^{\circ} 06^{\prime} 07,3^{\prime \prime} \mathrm{N}$ & $60^{\circ} 49^{\prime} 14,99^{\prime \prime} \mathrm{W}$ \\
\hline 4 & Boa Vista & $02^{\circ} 48^{\prime} 09,11^{\prime \prime} \mathrm{N}$ & $60^{\circ} 41^{\prime} 36,99^{\prime \prime} \mathrm{W}$ \\
\hline 5 & Boa Vista & $02^{\circ} 51^{\prime} 05,99^{\prime \prime} \mathrm{N}$ & $60^{\circ} 39^{\prime} 04,8^{\prime \prime} \mathrm{W}$ \\
\hline 6 & Boa Vista & $02^{\circ} 51^{\prime} 01,99^{\prime \prime} \mathrm{N}$ & $60^{\circ} 39^{\prime} 04,8^{\prime \prime} \mathrm{W}$ \\
\hline 7 & Boa Vista & $02^{\circ} 50^{\prime} 04,99^{\prime \prime} \mathrm{N}$ & $60^{\circ} 40^{\prime} 11,2^{\prime \prime} \mathrm{W}$ \\
\hline 8 & Boa Vista & $02^{\circ} 50^{\prime} 08,6^{\prime \prime} \mathrm{N}$ & $60^{\circ} 41^{\prime} 25,33^{\prime \prime} \mathrm{W}$ \\
\hline 9 & Boa Vista & $02^{\circ} 48^{\prime} 11,0^{\prime \prime} \mathrm{N}$ & $60^{\circ} 41^{\prime} 34,6$ '” \\
\hline 10 & Boa Vista & $02^{\circ} 48^{\prime} 44,5^{\prime \prime} \mathrm{N}$ & $60^{\circ} 40^{\prime} 57,8^{\prime \prime} \mathrm{W}$ \\
\hline 11 & Amajarí & $03^{\circ} 34^{\prime} 0,99^{\prime \prime} \mathrm{N}$ & $60^{\circ} 56^{\prime} 38,7 ’ \mathrm{~W}$ \\
\hline 12 & Amajarí & $03^{\circ} 34^{\prime} 20,1^{\prime \prime} \mathrm{N}$ & $60^{\circ} 56^{\prime} 44,3^{\prime \prime} \mathrm{W}$ \\
\hline
\end{tabular}

Para a seleção de cores das sementes das 12 matrizes realizou-se classificação manual, com auxílio de uma lupa dividindo-se para cada matriz sementes de cor laranja e vermelha, totalizando 500 sementes para cada cor. Em seguida, as sementes foram colocadas na bandeja do aparelho de análise de morfologia externa de sementes Groundeye ${ }^{\circledR}$, que contém uma câmera de alta resolução ligada a um computador que permite a visualização e análise das sementes em tempo real por meio de um software de análise de imagens próprio. Através desse software pode-se realizar uma classificação mais detalhada das sementes quanto à cor, utilizando o sistema de cores HSB para a matiz (tonalidade) e o brilho, e o sistema RGB para predominância da cor vermelha. 


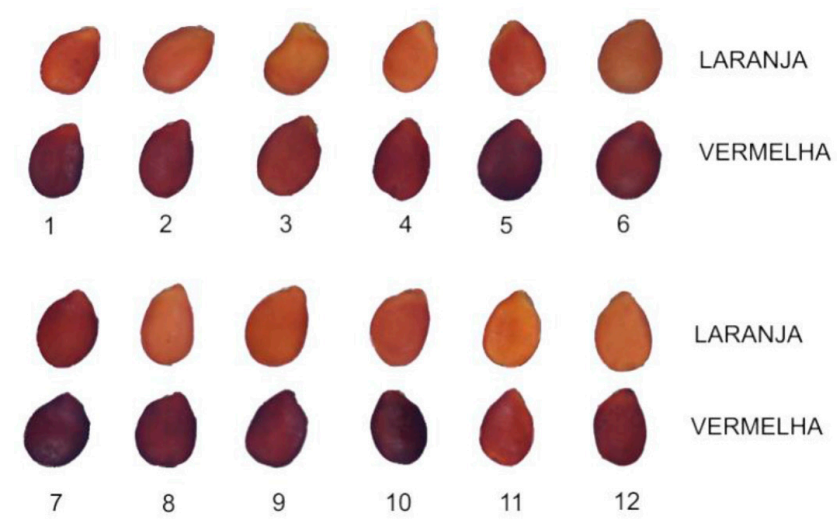

FIGURA 1: Sementes de paricarana classificadas pela cor do tegumento (laranja e vermelha) de 12 matrizes coletadas em Boa Vista e no município do Amajarí, Roraima, 2014.

FIGURE 1: Paricarana seeds classified by tegument color (orange and red) from 12 matrices collected in Boa Vista and Amajarí, Roraima state, 2014.

Os parâmetros de matiz, brilho e predominância de cor são baseados em escalas de 0 a 360 (matiz), 0,0 a 1,0 (brilho) e 0 a 255 (predominância de cor) relacionadas aos pixels da imagem. Para matiz, quanto menor este valor a tonalidade da semente será mais clara e quanto maior, mais escura, já em brilho e predominância de cor vermelho ocorre o inverso. Diante das imagens capturadas foram gerados relatórios com dados das características analisadas que variaram de acordo com a cor das sementes de cada matriz, como pode ser observado na Tabela 1 relacionando-se com a Figura 1.

TABELA 2: Classificação de cores das sementes de paricarana de acordo com os parâmetros básicos HSB - Matiz e Brilho e RGB - Predominância da cor vermelha, UFLA, Lavras-MG, 2014.

TABLE 2: Color classification of paricarana seeds according to HSB - Hue and Brightness, and RGB - Red color predominance parameters, UFLA, Lavras-MG state, 2014.

\begin{tabular}{ccccccc}
\hline & \multicolumn{2}{c}{ Matiz } & \multicolumn{2}{c}{ Brilho } & \multicolumn{2}{c}{ Cor vermelha } \\
\cline { 2 - 7 } Matriz & Laranja & Vermelha & Laranja & Vermelha & Laranja & Vermelha \\
\hline 1 & 93,17 & 288,23 & 0,41 & 0,34 & 112,45 & 90,37 \\
2 & 89,45 & 252,75 & 0,42 & 0,34 & 116,58 & 94,16 \\
3 & 36,84 & 78,44 & 0,47 & 0,42 & 130,25 & 115,83 \\
4 & 39,29 & 131,13 & 0,47 & 0,40 & 128,55 & 110,16 \\
5 & 100,10 & 326,00 & 0,40 & 0,30 & 110,16 & 75,94 \\
6 & 77,56 & 205,14 & 0,39 & 0,34 & 110,27 & 95,54 \\
7 & 306,03 & 325,37 & 0,28 & 0,21 & 76,81 & 48,77 \\
8 & 80,04 & 288,21 & 0,42 & 0,33 & 117,51 & 93,25 \\
9 & 66,63 & 272,76 & 0,43 & 0,32 & 120,00 & 92,71 \\
10 & 261,03 & 329,89 & 0,34 & 0,27 & 91,62 & 70,94 \\
11 & 37,28 & 62,61 & 0,50 & 0,45 & 138,55 & 122,96 \\
12 & 36,59 & 181,07 & 0,48 & 0,37 & 129,80 & 102,94 \\
\hline
\end{tabular}

Em que: As médias de matiz, brilho e cor vermelha são referentes a valores que variaram entre 0 a 360, 0,0 a 1,0 e 0 a 255 , respectivamente. 
O delineamento experimental estabelecido foi inteiramente casualizado, em arranjo fatorial $12 \times 2$ (matrizes x cores) com quatro repetições. As avaliações realizadas foram:

Morfometria de sementes: utilizou-se o mesmo aparelho e software (Groundeye ${ }^{\circledR}$ ) para classificação das cores das sementes, as quais foram dispostas aleatoriamente na bandeja do aparelho, no qual se capturaram as imagens para análise da morfométrica. As características da morfometria selecionadas para análise foram o diâmetro máximo e mínimo de cada semente das duas cores das 12 matrizes. Foram utilizadas quatro repetições de 50 sementes para cada matriz e suas cores, ao final da captura das imagens, o software gerou relatórios com as informações extraídas das características avaliadas, os resultados foram expressos em centímetros.

Raios-x: utilizou-se o aparelho Faxitron X - Ray com ajuste automático de intensidade de radiação ( $26 \mathrm{Kvp}$ ) e tempo de exposição (19 segundos). Para cada cor de cada matriz separaram-se quatro repetições de 50 sementes, que foram dispostas em fita dupla face sobre folha de transparência e feitas as radiografias. Contabilizou-se o número de sementes cheias, com os resultados expressos em porcentagem.

Germinação: para a montagem do teste as sementes foram submetidas ao tratamento de superação de dormência com água a $100^{\circ} \mathrm{C}$ por 10 segundos de acordo com Smiderle e Schwengber (2011), em seguida foram imersas em hipoclorito a $2 \%$ por 5 minutos, para controle de fungos, e posterior lavagem para a retirada do produto. Em seguida, as sementes foram semeadas em substrato papel germitest umedecido com água destilada 2,5 vezes o peso do papel seco (BRASIL, 2009), e mantidas em germinador a temperatura constante de $25^{\circ} \mathrm{C}$. Utilizaram-se quatro repetições de 50 sementes para cada cor e matriz com contagens diárias até o $14^{\circ}$ dia após o início do teste. Além da germinação, foi avaliado o número de sementes duras, embebidas, mortas e plântulas anormais, cujos resultados foram expressos em porcentagem.

Velocidade de sementes embebidas: conduzido conjuntamente com a germinação anotando-se diariamente o número de sementes embebidas, as sementes de paricarana após a embebição adquirem a coloração preta independentemente da cor original da semente, esta característica foi utilizada para determinação de sementes embebidas. Ao final do teste calculou-se o índice, segundo Maguire (1962), através do somatório do número de sementes embebidas em cada dia, dividido pelo número de dias decorridos entre a semeadura e a embebição das sementes.

Velocidade de germinação: conduzido conjuntamente com o teste de germinação anotando-se diariamente o número de sementes germinadas. Ao final do teste calculou-se o índice, através do somatório do número de sementes germinadas em cada dia, dividido pelo número de dias decorridos entre a semeadura e a germinação (MAGUIRE, 1962).

Morfometria das plântulas: foram utilizadas quatro repetições de 30 plântulas aproveitadas do teste de germinação no $14^{\circ}$ dia, para a realização da morfometria das mesmas, as plântulas foram retiradas cuidadosamente do papel germitest e colocadas na bandeja do aparelho Groundeye $\AA$, sem que elas se tocassem. Aanálise das imagens para a avaliação do comprimento das plântulas foi realizada automaticamente pelo software do aparelho, em que se avaliou o comprimento do hipocótilo/coleóptilo e radícula, sendo os dados em centímetros.

Microscopia eletrônica de varredura: as sementes foram imersas em nitrogênio líquido e cortadas ao meio com auxílio de um bisturi, utilizaram-se duas sementes de cada cor das 12 matrizes, após o corte foram imersas em solução fixativa (Karnovisk`s), pH 7,2, por 24 horas. Em seguida, foram lavadas em tampão cacodilato por três vezes, durante 10 minutos. A pós-fixação foi feita em tetróxido de ósmio $1 \%$ por uma hora e após esse período feitas lavagens com água destilada e desidratação em gradiente de acetona a 25, 50, 75, 90 e 100\%, por três vezes. As amostras foram levadas para o aparelho de ponto crítico, no 
qual foi eliminado todo o resíduo de acetona, para posterior montagem em stubs sob fita de carbono e revestimento com ouro. A visualização das amostras foi feita em microscópio eletrônico de varredura LEO Evo40 e foram avaliadas a morfologia e a espessura do tegumento.

Os resultados obtidos nas avaliações, com exceção da microscopia, foram submetidos à análise de variância e a comparação de médias, com nível de significância a 5\%, pelo teste de Scott-Knott, com auxílio do software SISVAR (FERREIRA, 2011).

\section{RESULTADOS E DISCUSSÃO}

$\mathrm{Na}$ análise dos quadrados médios observaram-se em cada variável diferenças significativas na interação dos fatores em estudo (cor x matriz) para a maioria das variáveis, exceto para morfometria do diâmetro mínimo da semente, em que mesmo sem ter havido interação, os fatores isolados foram significativos. Baseando-se nesses resultados pode-se verificar a importância de cada fator em questão para a determinação da qualidade física e fisiológica de sementes de paricarana.

A primeira característica estudada foi a morfometria das sementes com auxílio do aparelho e software Groundeye ${ }^{\circledR}$, que realizou medições do diâmetro máximo na vertical e mínimo na horizontal de cada semente (Figura 2).

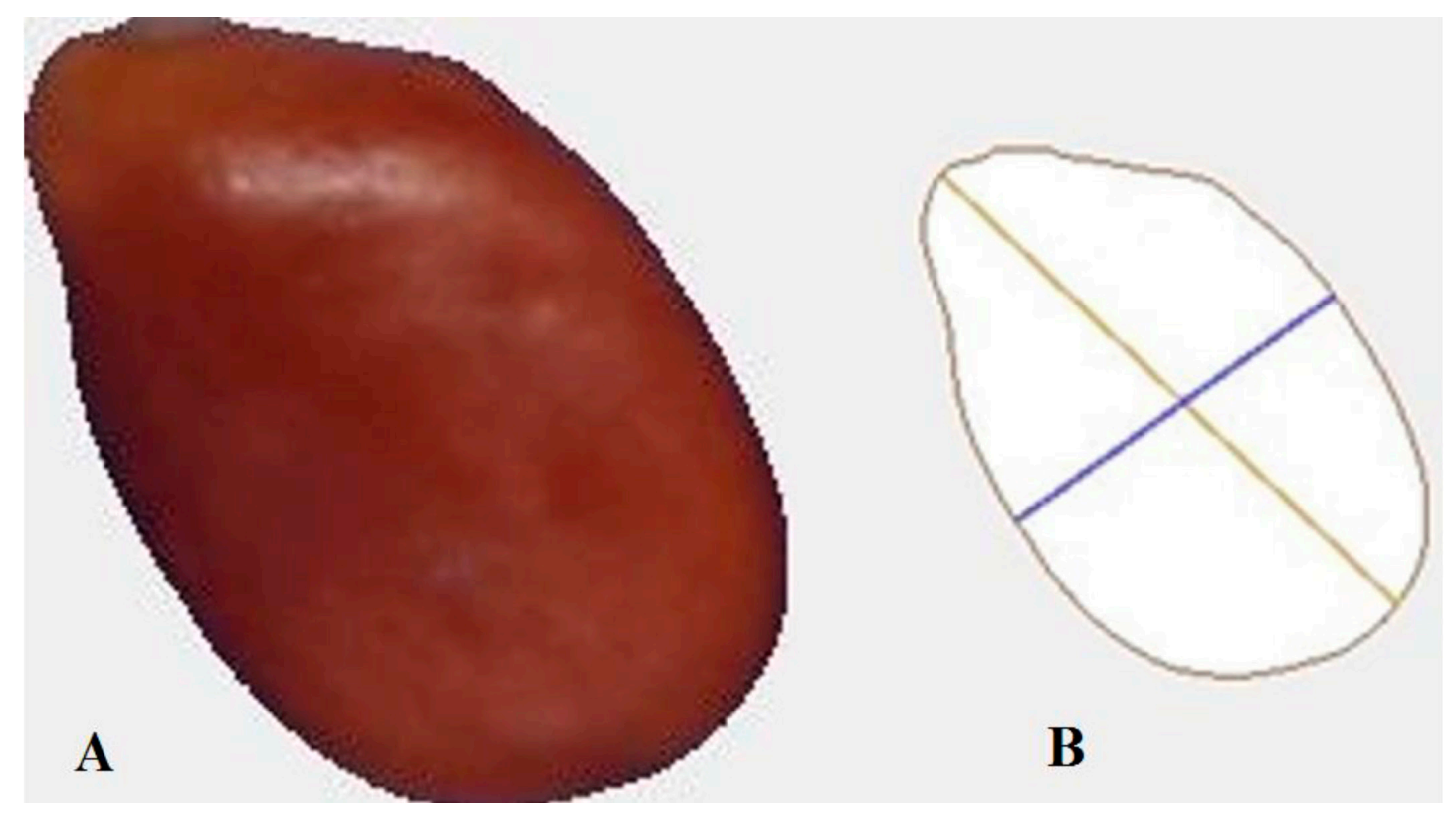

FIGURA 2: Imagem obtida do software Groundeye ${ }^{\circledR}$ mostrando o diâmetro máximo (A) e mínimo (B) da semente de paricarana. UFLA, Lavras-MG, 2014.

FIGURE2: Measurement ofmaximum(A) and minimum(B) diameter of paricarana seed obtained by the Groundeye (R) software. UFLA, Lavras-MG state, 2014.

A partir dessas imagens pôde-se observar na comparação entre matrizes de sementes cor laranja, que a matriz 11 foi superior em diâmetro máximo $(0,52 \mathrm{~cm})$ e as matrizes 5 e $6(0,36 \mathrm{~cm})$ tiveram maior diâmetro mínimo em relação às demais (Tabela 3$)$. Já as sementes de cor vermelha das matrizes 2 e $11(0,52$ $\mathrm{cm}$, ambas) se destacaram em diâmetro máximo, e as matrizes 2, 5, 6, 10 e 11 em diâmetro mínimo (0,32 $\mathrm{cm})$.

Na comparação de cores para diâmetro máximo verificaram-se diferenças significativas na matriz 2 , em que as sementes de cor laranja $(0,51 \mathrm{~cm})$ atingiram menor diâmetro em relação às sementes de cor vermelha $(0,52 \mathrm{~cm})$, já nas matrizes 5,8 e 9 para sementes de cor laranja ocorreu o inverso. No diâmetro mínimo observou-se menor diâmetro para sementes de cor vermelha das matrizes 1, 3, 5 e 6 comparado 
com as sementes de cor laranja. Dentre as matrizes estudadas para as duas cores observou-se maior tamanho da semente para a matriz 11 e menor tamanho matriz 7, com isso, verificou-se a diversidade de tamanhos que as sementes podem apresentar entre matrizes e dentro de uma mesma matriz, observando-se maior diferença nas medidas de todas as matrizes para o diâmetro máximo das sementes. Gonçalves et al. (2008) obtiveram resultados próximos avaliando diâmetro máximo $(0,49 \mathrm{~cm})$ e mínimo $(0,35 \mathrm{~cm})$ de sementes de 10 matrizes de paricarana na cidade de Cuiabá-MT, que possui condições climáticas e ambientais similares aos da região de coleta das sementes deste trabalho.

TABELA 3: Valores médios de diâmetro máximo, mínimo, raios-x e velocidade de sementes embebidas, de sementes de paricarana com duas cores (laranja e vermelho), provenientes de 12 matrizes coletadas em Boa Vista e Amajarí, Roraima, 2014.

TABLE 3: Mean values of maximum and minimum diameter, $\mathrm{x}$-rays, and speed of soaked seed obtained from two colors (orange and red) of 12 matrices of paricarana seeds, collected in Boa Vista and Amajarí, Roraima state, 2014.

\begin{tabular}{|c|c|c|c|c|c|c|c|c|}
\hline \multirow[b]{2}{*}{ Matriz } & \multicolumn{2}{|c|}{$\operatorname{MAX}(\mathrm{cm})$} & \multicolumn{2}{|c|}{ MIN (cm) } & \multicolumn{2}{|c|}{$\mathrm{RX}(\%)$} & \multicolumn{2}{|c|}{ VE (índice) } \\
\hline & Laranja & Vermelha & Laranja & Vermelha & Laranja & Vermelha & Laranja & Vermelha \\
\hline 1 & $0,51 \mathrm{bA}$ & $0,51 \mathrm{bA}$ & $0,35 \mathrm{bA}$ & $0,34 \mathrm{bB}$ & $98 \mathrm{aA}$ & $95 \mathrm{bA}$ & $8,99 \mathrm{dA}$ & $9,36 \mathrm{cA}$ \\
\hline 2 & $0,51 \mathrm{bB}$ & $0,52 \mathrm{aA}$ & $0,35 \mathrm{bA}$ & $0,35 \mathrm{aA}$ & $86 \mathrm{bA}$ & $71 \mathrm{cB}$ & $11,49 \mathrm{bA}$ & $10,82 \mathrm{bB}$ \\
\hline 3 & $0,49 \mathrm{cA}$ & $0,49 \mathrm{cA}$ & $0,35 \mathrm{bA}$ & $0,34 \mathrm{bB}$ & $98 \mathrm{aA}$ & $98 \mathrm{aA}$ & $11,16 \mathrm{bA}$ & $10,82 \mathrm{bB}$ \\
\hline 4 & $0,49 \mathrm{cA}$ & $0,49 \mathrm{cA}$ & $0,34 \mathrm{cA}$ & $0,34 \mathrm{bA}$ & $100 \mathrm{aA}$ & $100 \mathrm{aA}$ & $12,27 \mathrm{aA}$ & $12,44 \mathrm{aA}$ \\
\hline 5 & $0,49 \mathrm{cA}$ & $0,47 \mathrm{~dB}$ & $0,36 \mathrm{aA}$ & $0,35 \mathrm{aB}$ & $100 \mathrm{aA}$ & $84 \mathrm{bB}$ & $11,42 \mathrm{bB}$ & $12,06 \mathrm{aA}$ \\
\hline 6 & $0,47 \mathrm{dA}$ & $0,47 \mathrm{dA}$ & $0,36 \mathrm{aA}$ & $0,35 \mathrm{aB}$ & $93 \mathrm{bA}$ & $84 \mathrm{bB}$ & $11,68 \mathrm{bB}$ & $12,20 \mathrm{aA}$ \\
\hline 7 & $0,43 \mathrm{eA}$ & $0,43 \mathrm{fA}$ & $0,32 \mathrm{dA}$ & $0,32 \mathrm{cA}$ & $100 \mathrm{aA}$ & $95 \mathrm{bA}$ & $12,32 \mathrm{aA}$ & $12,37 \mathrm{aA}$ \\
\hline 8 & $0,47 \mathrm{dA}$ & $0,46 \mathrm{eB}$ & $0,32 \mathrm{dA}$ & $0,32 \mathrm{cA}$ & $100 \mathrm{aA}$ & $98 \mathrm{aA}$ & $10,04 \mathrm{cA}$ & $10,47 \mathrm{bA}$ \\
\hline 9 & $0,47 \mathrm{dA}$ & $0,46 \mathrm{eB}$ & $0,32 \mathrm{dA}$ & $0,32 \mathrm{cA}$ & $100 \mathrm{aA}$ & $98 \mathrm{aA}$ & $9,56 \mathrm{cA}$ & $9,81 \mathrm{cA}$ \\
\hline 10 & $0,47 \mathrm{dA}$ & $0,47 \mathrm{dA}$ & $0,35 \mathrm{bA}$ & $0,35 \mathrm{aA}$ & $96 \mathrm{aA}$ & $96 \mathrm{bA}$ & $7,86 \mathrm{dA}$ & $8,12 \mathrm{dA}$ \\
\hline 11 & $0,52 \mathrm{aA}$ & $0,52 \mathrm{aA}$ & $0,35 \mathrm{bA}$ & $0,35 \mathrm{aA}$ & $90 \mathrm{bA}$ & $91 \mathrm{bA}$ & $6,97 \mathrm{~dB}$ & $7,86 \mathrm{dA}$ \\
\hline 12 & $0,49 \mathrm{cA}$ & $0,49 \mathrm{cA}$ & $0,34 \mathrm{cA}$ & $0,34 \mathrm{bA}$ & $100 \mathrm{aA}$ & $100 \mathrm{aA}$ & $12,34 \mathrm{aA}$ & $12,44 \mathrm{aA}$ \\
\hline Média & 0,48 & 0,48 & 0,34 & 0,33 & 97 & 93 & 10,51 & 10,73 \\
\hline C.V.\% & \multicolumn{2}{|c|}{1,15} & \multicolumn{2}{|c|}{1,4} & \multicolumn{2}{|c|}{3,81} & \multicolumn{2}{|c|}{3,18} \\
\hline
\end{tabular}

Em que: $\mathrm{MAX}=$ diâmetro máximo, $\mathrm{MIX}=$ diâmetro mínimo, $\mathrm{RX}=$ raios-X, $\mathrm{VE}=$ velocidade de sementes embebidas. Na coluna, médias seguidas de letras distintas minúsculas diferem significativamente entre matrizes e maiúsculas na linha diferem entre cores pelo teste de Scott-Knott a 5\% de probabilidade.

Na avaliação das estruturas internas das sementes com a utilização do aparelho de raios-x (Tabela 3), observou-se entre matrizes para sementes de cor laranja que a presença de danos físicos foi maior nas matrizes 2,6 e 11, e para sementes de cor vermelha, a matriz 2 foi a que apresentou menor qualidade física das sementes. Quando comparadas as cores verificou-se diferença significativa nas matrizes 2,5 e 6 , em que as sementes de cor laranja apresentaram melhor qualidade física em relação às de cor vermelha. As radiografias mostraram boa qualidade física das sementes para as duas cores na maioria das matrizes, sendo os danos encontrados causados por ataques de insetos, à matriz 2 foi a que teve maior número de sementes infestadas por insetos nas duas cores de sementes. Portanto, os valores de qualidade física das sementes das diferentes matrizes corroboraram a avaliação da qualidade fisiológica.

Albuquerque e Guimarães, (2008) trabalhando com três lotes de sementes de paricarana, observaram diferenças de qualidade física com auxílio do aparelho de raios-x e sua relação com a qualidade fisiológica, em Lavras-MG. Masetto, Faria e Queiroz (2008) trabalhando com sementes de Cedrela fissilis constataram diferenças na qualidade física com o auxílio do aparelho de raios-x, assim como, Souza et al. (2008) utilizando sementes de Platypodium elegans. Lima et al. (2013) em sua revisão literária e Tonetti, David 
e Silva (2006) trabalhando com qualidade física de sementes de Eremanthus erythropappus, apontaram o teste utilizando radiografias como sendo o mais eficiente, por ser um método não destrutivo e capaz de identificar a qualidade física das sementes.

Outro fator importante estudado foi a velocidade em que as sementes foram embebidas durante a germinação (Tabela 3), observou-se que em sementes de cor laranja, as matrizes 4, 7 e 12 atingiram o maior índice de sementes embebidas após a superação da dormência, e em sementes de cor vermelha as matrizes 4, 5, 6, 7 e 12 obtiveram índices acima de 12 , sendo superior às demais. Com isso, pode-se observar a variação na velocidade de embebição entre as diferentes matrizes em resposta ao tratamento de remoção da camada impermeável das sementes, sendo este mais eficiente para as matrizes 4,7 e 12 , que obtiveram maior velocidade de sementes embebidas para as duas cores.

Na germinação (Tabela 4), observaram-se diferenças significativas na qualidade fisiológica das sementes de cor laranja e vermelha, tanto entre as matrizes quanto entre as cores. Entre as matrizes das sementes de cor laranja, as que se destacaram foram 3, 4, 6 e 12 e para sementes de cor vermelha 1,4 e 12. Com relação às cores pode-se observar que sementes de cor laranja atingiram maior porcentagem de germinação $(88 \%)$ do que as de cor vermelha $(80 \%)$. Verificou-se a relação da variável radiografia com a germinação, observando-se que a qualidade física não foi o fator agravante de redução da mesma para a maioria das matrizes, com exceção para a matriz 2, em que o ataque por insetos ocasionou os danos que consequentemente afetaram a qualidade fisiológica. Pode-se considerar, portanto, que o efeito do tratamento de superação de dormência das sementes e/ou cor das sementes foram os fatores que influenciaram na qualidade fisiológica.

Resultados obtidos por Dalanhol et al. (2014) com três cores (amarela, laranja e vermelha/preta) de sementes de paricarana no Paraná, constataram diferenças significativas, sendo as sementes de cor amarela e laranja mais vigorosas do que as de cor vermelha/preta. Smiderle e Schwengber (2011) trabalhando com superação de dormência em sementes de paricarana em Boa Vista-RR obtiveram resultados próximos aos deste trabalho utilizando tratamento similar, com água a $100^{\circ} \mathrm{C}$ por 10 segundos +1 minuto de imersão em hipoclorito de sódio. Já Albuquerque et al. (2007) obtiveram menor percentual de germinação de sementes de sucupira-preta utilizando tratamentos com ácido sulfúrico, água a $80^{\circ} \mathrm{C}$ e escarificação mecânica, quando comparando aos dados desta pesquisa.

Smiderle, Mourão Júnior e Sousa (2005) trabalhando com sementes de Acacia mangium obtiveram valores acima de $80 \%$ de germinação utilizando tratamento com água a $100^{\circ} \mathrm{C}$ por um minuto. Rodrigues et al. (2008) obtiveram valores decrescentes de germinação utilizando sementes de acácia com o tratamento de água a $100^{\circ} \mathrm{C}$ por 15,30 e 60 segundos. Isto mostra que o tempo de permanência das sementes em água fervente pode danificar as membranas celulares ocasionando baixa germinação ou morte das mesmas, como foi observado por Smiderle e Schwengber (2011). Para as sementes de paricarana utilizadas neste trabalho, o tempo de 10 segundos foi eficiente na superação de dormência para a maioria das matrizes, com destaque 
para as sementes de cor laranja, que responderam melhor ao tratamento.

TABELA 4: Valores médios de germinação, velocidade de germinação, comprimento de hipocótilo/coleóptilo e comprimento de radícula de sementes de paricarana com duas cores (laranja e vermelha), provenientes de 12 matrizes coletadas em Boa Vista e Amajarí, Roraima, 2014.

TABLE 4: Mean values of germination, speed of germination, hypocotyl/coleoptile length, and radicle length obtained from two colors (orange and red) of 12 matrices of paricarana seeds, collected in Boa Vista and Amajarí, Roraima state, 2014.

\begin{tabular}{ccccccccc}
\hline & \multicolumn{2}{c}{ GERM (\%) } & \multicolumn{2}{c}{ VG (índice) } & \multicolumn{2}{c}{ CHC (cm) } & \multicolumn{2}{c}{ CR (cm) } \\
\cline { 2 - 9 } Matriz & Laranja & Vermelha & Laranja & Vermelha & Laranja & Vermelha & Laranja & Vermelha \\
\hline 1 & $89 \mathrm{bA}$ & $91 \mathrm{aA}$ & $3,95 \mathrm{bB}$ & $4,33 \mathrm{bA}$ & $1,33 \mathrm{cB}$ & $1,72 \mathrm{cA}$ & $2,54 \mathrm{~dB}$ & $3,22 \mathrm{eA}$ \\
2 & $77 \mathrm{cA}$ & $68 \mathrm{~dB}$ & $3,74 \mathrm{cA}$ & $3,00 \mathrm{~dB}$ & $1,62 \mathrm{bA}$ & $1,69 \mathrm{cA}$ & $4,31 \mathrm{aA}$ & $3,34 \mathrm{eB}$ \\
3 & $95 \mathrm{aA}$ & $83 \mathrm{bB}$ & $4,73 \mathrm{aA}$ & $4,12 \mathrm{bB}$ & $1,70 \mathrm{bA}$ & $1,67 \mathrm{cA}$ & $4,33 \mathrm{aA}$ & $4,09 \mathrm{cA}$ \\
4 & $97 \mathrm{aA}$ & $97 \mathrm{aA}$ & $4,82 \mathrm{aA}$ & $4,83 \mathrm{aA}$ & $1,99 \mathrm{aA}$ & $2,04 \mathrm{aA}$ & $4,61 \mathrm{aA}$ & $4,76 \mathrm{aA}$ \\
5 & $92 \mathrm{bA}$ & $84 \mathrm{bB}$ & $4,42 \mathrm{bA}$ & $4,11 \mathrm{bA}$ & $1,57 \mathrm{bA}$ & $1,43 \mathrm{~dB}$ & $4,51 \mathrm{aA}$ & $3,37 \mathrm{eB}$ \\
6 & $96 \mathrm{aA}$ & $88 \mathrm{bB}$ & $4,24 \mathrm{bA}$ & $3,61 \mathrm{~dB}$ & $1,39 \mathrm{cA}$ & $1,15 \mathrm{eB}$ & $3,13 \mathrm{cA}$ & $2,58 \mathrm{fB}$ \\
7 & $90 \mathrm{bA}$ & $70 \mathrm{~dB}$ & $4,55 \mathrm{aA}$ & $3,39 \mathrm{~dB}$ & $1,65 \mathrm{bA}$ & $1,58 \mathrm{cA}$ & $3,37 \mathrm{cA}$ & $2,72 \mathrm{fB}$ \\
8 & $84 \mathrm{bA}$ & $78 \mathrm{cA}$ & $4,16 \mathrm{bA}$ & $3,91 \mathrm{cA}$ & $1,72 \mathrm{bA}$ & $1,65 \mathrm{cA}$ & $3,93 \mathrm{bA}$ & $3,76 \mathrm{dA}$ \\
9 & $90 \mathrm{bA}$ & $79 \mathrm{cB}$ & $4,37 \mathrm{bA}$ & $3,84 \mathrm{cB}$ & $1,63 \mathrm{bA}$ & $1,47 \mathrm{~dB}$ & $4,05 \mathrm{bA}$ & $3,16 \mathrm{eB}$ \\
10 & $69 \mathrm{cA}$ & $67 \mathrm{dA}$ & $2,99 \mathrm{dA}$ & $3,01 \mathrm{eA}$ & $1,39 \mathrm{cA}$ & $1,40 \mathrm{dA}$ & $4,50 \mathrm{aA}$ & $4,33 \mathrm{bA}$ \\
11 & $74 \mathrm{cA}$ & $68 \mathrm{dA}$ & $3,00 \mathrm{dA}$ & $3,06 \mathrm{eA}$ & $1,06 \mathrm{~dB}$ & $1,38 \mathrm{dA}$ & $2,43 \mathrm{~dB}$ & $3,07 \mathrm{eA}$ \\
12 & $99 \mathrm{aA}$ & $94 \mathrm{aA}$ & $4,94 \mathrm{aA}$ & $4,68 \mathrm{aA}$ & $1,92 \mathrm{aA}$ & $1,90 \mathrm{bA}$ & $4,80 \mathrm{aA}$ & $4,46 \mathrm{bB}$ \\
\hline Média & 88 & 80 & 4,16 & 3,85 & 1,58 & 1,59 & 3,87 & 3,57 \\
\hline C.V.\% & \multicolumn{9}{c}{5,54} & \multicolumn{7}{c}{5,18} & & 6,05 \\
\hline
\end{tabular}

Em que: GERM = germinação, $\mathrm{VG}=$ velocidade de germinação, $\mathrm{CHC}=$ comprimento hipocótilo/coleóptilo e $\mathrm{CR}=$ comprimento de radícula. Na coluna, médias seguidas de letras distintas minúsculas diferem significativamente entre matrizes e maiúsculas na linha diferem entre cores pelo teste de Scott-Knott a 5\% de probabilidade.

$\mathrm{Na}$ velocidade de germinação (Tabela 4) das sementes de cor laranja, as matrizes 3, 4, 7 e 12 obtiveram os maiores índices com relação às demais matrizes, e nas sementes de cor vermelha os melhores índices foram para as matrizes 4 e 12. Verificou-se que quando comparadas as cores, as sementes de cor laranja foram superiores em desempenho do que as de cor vermelha para todas as matrizes, exceto matriz $1 \mathrm{em}$ que ocorreu o inverso. O mesmo foi observado por Dalanhol et al. (2014) utilizando sementes de paricarana de diferentes cores no Paraná. Já Albuquerque et al. (2007) observaram menores índices de velocidade de germinação para sementes de sucupira-preta utilizando diferentes tratamentos de superação de dormência, em relação ao deste trabalho.

Outras duas características estudadas foram comprimento de hipocótilo/coleóptilo e radícula com o auxílio do Groundeye ${ }^{\circledR}$. Na Figura 3 pode ser verificado como foram realizadas as medições na plântula, a linha verde representa a medição do hipocótilo/coleóptilo e a linha azul radícula. Observou-se para comprimento do hipocótilo/coleóptilo (Tabela 4) que as plântulas oriundas de sementes de cor laranja das matrizes 4 e 12 obtiveram maior crescimento em relação às demais, e aquelas oriundas de sementes de cor vermelha, a matriz 4 se destacou das demais com 2,04 cm de crescimento do hipocótilo/coleóptilo. $\mathrm{Na}$ comparação de cores observaram-se diferenças significativas nas matrizes 1 e 11, em que o crescimento foi maior para as sementes de cor vermelha e nas matrizes 5, 6 e 9 ocorreu o inverso. Masetto et al. (2009) constataram diferenças de qualidade em lotes de sementes de Crambe Hochst abyssinica produzidas no Mato Grosso através da medição do comprimento do hipocótilo.

No comprimento de radícula (Tabela 4) as plântulas oriundas de sementes de cor laranja que 
atingiram o menor tamanho em relação às demais foram as das matrizes 1 e 11 , e nas plântulas oriundas de sementes de cor vermelha, 6 e 7. Quando comparadas as cores observou-se que as plântulas oriundas de sementes de cor laranja da maioria das matrizes tiveram maior radícula, sendo assim consideradas mais vigorosas, porque quanto maior a radícula melhor será a absorção de nutrientes e água, além de melhor fixação da plântula no solo.

$\mathrm{Na}$ comparação da germinação com a morfometria das plântulas pode-se observar a relação do vigor com o percentual de germinação, em sua maioria, sementes com maior comprimento de hipocótilo/ coleóptico e radícula atingiram germinação superior. $\mathrm{O}$ uso do Grouneye ${ }^{\circledR}$ para a avaliação de plântulas foi um método eficiente e preciso para determinar o vigor.

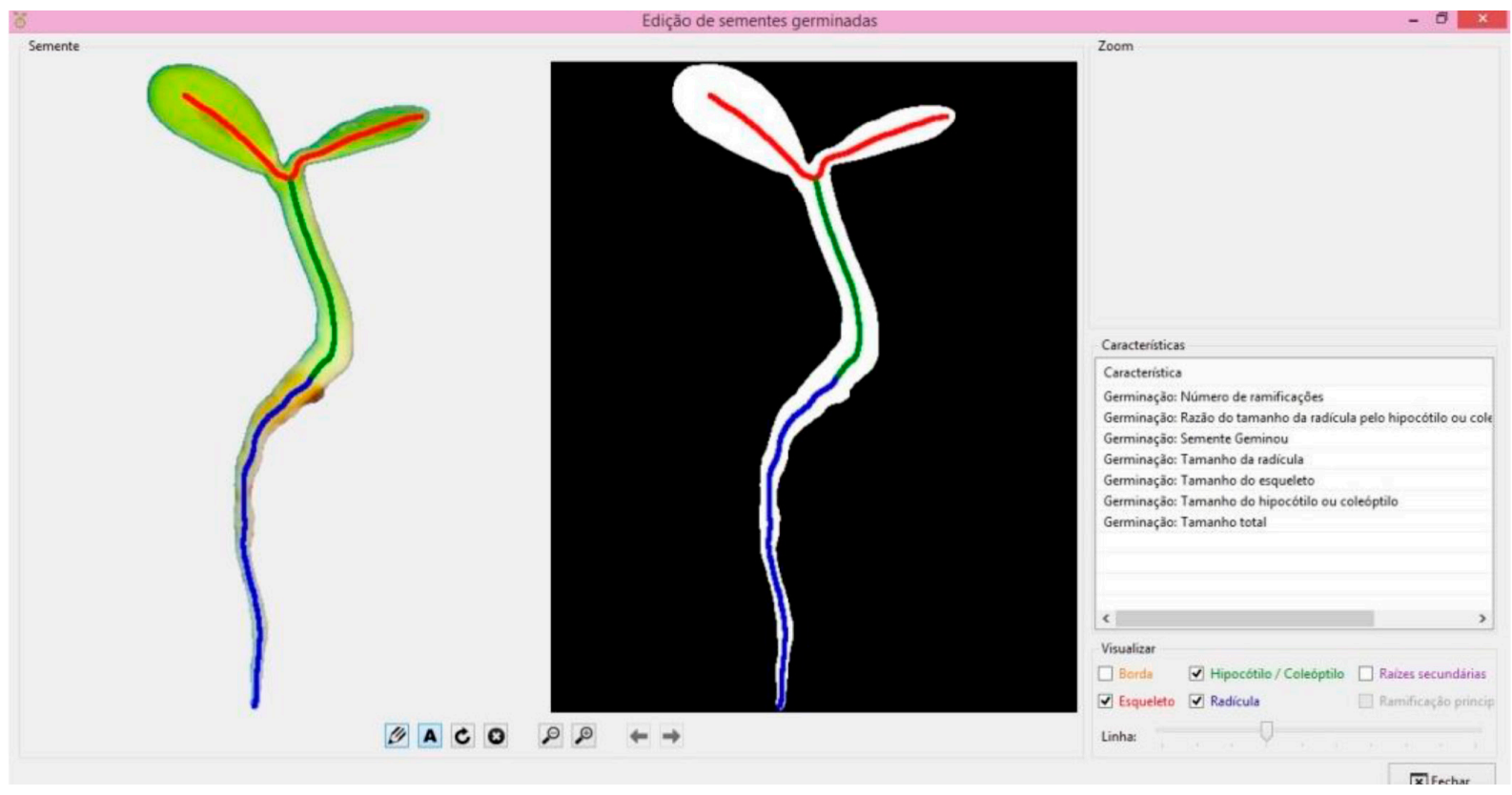

FIGURA 3: Comprimento do hipocótilo/coleóptilo (linha verde) e da radícula (linha azul) da plântula de paricarana, obtidos do software Groundeye ${ }^{\circledR}$. UFLA, Lavras-MG, 2014.

FIGURE 3: Length of hypocotyl/coleoptile (green line) and radicle (blue line) of paricarana seedling obtained by Groundeye ${ }^{\circledR}$ software. UFLA, Lavras-MG state, 2014.

As sementes duras, embebidas, mortas e plântulas anormais (Tabela 5) também foram avaliadas com o intuito de verificar a influência do tratamento de superação de dormência na germinação das sementes nas 12 matrizes e diferentes cores. Verificou-se em sementes duras que as matrizes 10 e 11 atingiram percentual maior para as duas cores, categorizando menor eficiência do tratamento na remoção da camada impermeável. As matrizes 2, 6, 7, 8 e 9 de sementes de cor vermelha também apresentaram maior número de sementes duras com percentuais próximos a 10\%, constatando-se, portanto, maior impermeabilidade do tegumento para as sementes destas matrizes, provavelmente, para as matrizes 2, 6, 7, 8 e 9, o aumento do tempo em água a $100^{\circ} \mathrm{C}$ poderia ser recomendado para retirar melhor a mucilagem e permitir a germinação.

Em sementes embebidas, observou-se que as matrizes 10 e 11 atingiram maior porcentagem tanto para sementes de cor laranja quanto para cor vermelha, já na matriz 3, apenas para sementes de cor vermelha, podendo-se considerar que estas matrizes ainda têm alguma dormência no tegumento. Para sementes mortas, apenas a matriz 2 mostrou número considerável de $11 \%$ em sementes de cor laranja e $22 \%$ nas de cor vermelha, justificado pelo efeito do ataque por insetos às sementes dessa matriz. A presença de plântulas anormais foi maior nas matrizes 7,8 e 9 , podendo ser causada pela baixa qualidade das sementes ou consequência do tratamento de superação de dormência.

A germinação das sementes não foi afetada por infecção de fungos, portanto, o tratamento com hipoclorito foi eficiente no controle de patógenos. Pereira et al. (2014) obtiveram elevado número de sementes duras e embebidas trabalhando com 10 espécies de Fabaceae, utilizando tratamento térmico com 
água a $95^{\circ} \mathrm{C}$ para superação de dormência, o mesmo não foi observado nas sementes avaliadas para a maioria das matrizes de paricarana.

TABELA 5: Valores médios de sementes duras, embebidas, mortas e plântulas anormais de paricarana com duas cores de sementes (laranja e vermelha), provenientes de 12 matrizes coletadas em Boa Vista e Amajarí, Roraima, 2014.

TABLE 5: Mean values of hard, soaked and dead seeds, and abnormal seedlings obtained from two colors (orange and red) of 12 matrices of paricarana seeds, collected in Boa Vista and Amajarí, Roraima state, 2014.

\begin{tabular}{|c|c|c|c|c|c|}
\hline \multicolumn{3}{|c|}{ Temperatura de $105^{\circ} \mathrm{C}$} & \multicolumn{3}{|c|}{ Temperatura de $95^{\circ} \mathrm{C}$} \\
\hline \multirow{2}{*}{$\begin{array}{l}\mathrm{H}_{2} \mathrm{O}_{2} \\
(\mathrm{~kg} / \mathrm{t})\end{array}$} & Com Pressão & Sem Pressão & \multirow{2}{*}{$\begin{array}{l}\mathrm{H}_{2} \mathrm{O}_{2} \\
(\mathrm{~kg} / \mathrm{t})\end{array}$} & Com Pressão & Sem Pressão \\
\hline & \multicolumn{2}{|c|}{ Viscosidade (cP) } & & \multicolumn{2}{|c|}{ Viscosidade (cP) } \\
\hline 3 & $16,65(0,93)$ & $17,05(0,47)$ & 3 & $17,10(1,12)$ & $17,20(0,37)$ \\
\hline 6 & $15,83(0,15)$ & $15,68(0,28)$ & 6 & $16,70(1,53)$ & $16,03(0,86)$ \\
\hline
\end{tabular}

Em que: $\mathrm{SD}=$ duras, $\mathrm{EMB}=$ embebidas, $\mathrm{MORT}=$ mortas e $\mathrm{ANOR}=$ plântulas anormais. Os dados são médias percentuais.

$\mathrm{Na}$ avaliação da microscopia eletrônica de varredura observou-se a estrutura do tegumento das sementes de cor laranja e vermelha das 12 matrizes, e constatou-se diferença de espessura no tegumento, sendo este, mais espesso na vertical do que na horizontal (Figura 4A), porém, as medições realizadas em todas as matrizes, tiveram variação de espessura nas 12 matrizes não sendo possível relacionar com os testes fisiológicos, por não ter sido observado um padrão na espessura. Os valores variaram de $188,0 \mu \mathrm{m}$ a $620,1 \mu \mathrm{m}$ na vertical e de $111,7 \mu \mathrm{m}$ a $270,2 \mu \mathrm{m}$ na horizontal. A média geral de espessura na vertical para sementes de cor laranja foi $429,7 \mu \mathrm{m}$ e para sementes de cor vermelha $427,1 \mu \mathrm{m}$, na horizontal foi 149,5 $\mu \mathrm{m}$ e $150,8 \mu \mathrm{m}$, respectivamente.

No tegumento das sementes foi possível identificar três camadas, a epiderme da testa formada por macroesclereídes alongadas no sentido radial, hipoderme da testa formada apenas por uma camada de células colunares e as células parenquimatosas (Figura 4B), a camada mucilaginosa presente nas sementes e que é responsável por causar a impermeabilidade não foi visualizada através deste método. Mertz et al. (2009) conseguiram observar diferenças de estrutura do tegumento de sementes de soja-preta e amarela relacionadas à impermeabilidade utilizando microscopia eletrônica. O mesmo não foi observado nas duas cores de sementes estudadas, porque ambas tiveram as mesmas características no tegumento, podendo ser diferente apenas na quantidade de cutícula presente em cada cor, como pode ser observado maior número de sementes dormentes em sementes de cor vermelha para a maioria das matrizes. 


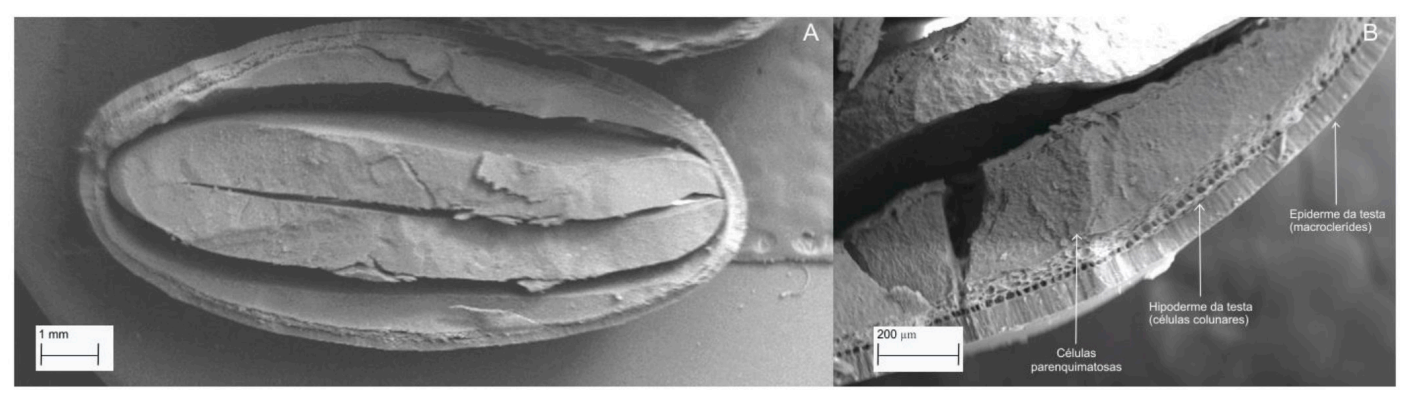

FIGURA 4: Imagens da estrutura do tegumento das sementes de paricarana, obtidas por meio de microscópio eletrônico de varredura. Aumento médio de 27X (A) e 181X (B). UFLA, Lavras-MG, 2014.

FIGURE 4: Images of the tegument structure of paricarana seed, obtained by a scanning electron microscope. Average increase of 27X (A) and 181X (B). UFLA, Lavras-MG state, 2014.

Pelos resultados da microscopia, verificou-se que uma matriz de paricarana pode produzir sementes de cores laranja e vermelha com diferentes espessuras de tegumentos, contudo, a espessura não parece ocasionar redução no desempenho fisiológico das sementes, devido à espessura do tegumento, no qual ocorre a protrusão da radícula (horizontal) não ser muito espessa comparado com a vertical, por isso, a quantidade de cutícula presente nas sementes continua sendo o maior impedimento para a germinação.

Os métodos utilizados para a caracterização das sementes foram eficientes mostrando as diferenças de qualidade física, fisiológica e vigor entre as matrizes e as cores, bem como o método de superação de dormência aplicado para remover a impermeabilidade do tegumento das sementes de paricarana promovendo a germinação acima de $70 \%$ para a maioria das matrizes nas duas cores, assim como, o método de desinfestação também foi eficiente no controle de patógenos.

As sementes de cor laranja reagiram melhor ao tratamento de superação de dormência além de apresentarem melhor qualidade fisiológica. As matrizes 4 e 12 foram as que obtiveram maior percentual de germinação e vigor para as duas cores, podendo essas duas matrizes serem utilizadas para a produção de mudas por apresentarem sementes de boa qualidade.

\section{CONCLUSÕES}

Os métodos utilizados para caracterização física das sementes de cor laranja e vermelha das 12 matrizes de paricarana são eficientes.

As sementes de paricarana de cor laranja têm melhor qualidade física e fisiológica.

$\mathrm{O}$ tratamento com água a $100^{\circ} \mathrm{C}$ por 10 segundos mais 5 minutos de imersão em hipoclorito a $2 \%$ é eficiente na superação de dormência e controle de patógenos das sementes de ambas as cores das 12 matrizes de paricarana.

\section{REFERÊNCIAS}

ALBUQUERQUE, K. S. et al. Métodos para a superação da dormência em sementes de sucupira-preta (Bowdichia virgilioides Kunth.). Ciência Agrotecnologica, Lavras, v. 31, n. 6, p. 1716-1721, nov. 2007. ALBUQUERQUE, K. S.; GUIMARÃES, R. M. Avaliação da qualidade de sementes de sucupira-preta (Bowdichia virgilioides Kunth.) pelo teste de Raios - X. Ciência Agrotecnologica, Lavras, v. 32, n. 6, p. 1713-1718, nov. 2008. 
BARBEDO, C. J.; BILIA, D. A. C.; FIQUEREDO-RIBEIRO, R. C. L. Tolerância à dessecação e armazenamento de sementes de Caesalpiniae chinata Lam. (pau-brasil), espécie da Mata Atlântica. Revista Brasileira de Botânica, São Paulo, v. 25, n. 4, p. 431-439, dez. 2002.

BRASIL. Ministério da Agricultura, Pecuária e Abastecimento. Regras para análise de sementes. Brasília: MAPA; ACS, 2009. 399 p.

CASTELLANI, E. D.; AGUIAR, I. B.; PAULA, R. C. Bases para a padronização do teste de germinação em três espécies de Solanum L. Revista Brasileira de Sementes, Londrina, v. 3, n. 2, p. 77-85, 2009.

DALANHOL, S. J. et al. Teste de Condutividade Elétrica em Sementes de Bowdichia virgilioides Kunth. Floresta e Ambiente, Rio de Janeiro, v. 1, n. 21, p. 69-77, jan. 2014.

FEITOSA, S. S. et al. Estudos de viabilidade de sementes de candeia Eremanthus erythropappus (DC.) Macleish por meio de testes de germinação e raios x. Floresta, Curitiba, v. 39, n. 2, p. 393-399, abr. 2009. FERREIRA, D. F. Sisvar: a computer statistic analysis system. Ciência Agrotecnologica, Lavras, v. 35, n. 6, p. 1039-1042, nov. 2011.

FIRATLIGIL-DURMUS, E. et al. Size properties of legume seeds of different varieties using image analysis. Journal of Food Engineering, Essex, v. 99, n. 4, p. 445-451, ago. 2010.

FLORES, A. V. et al. Efeito do substrato, cor e tamanho de sementes na germinação e vigor de Melanoxylon braúna. Pesquisa Florestal Brasileira, Colombo, v. 34, n. 78, p. 141-147, abr. 2014.

FORTI, V. A.; CICERO, S. M.; PINTO, T. L. F. Avaliação da evolução de danos por "umidade" e redução do vigor em sementes de soja, cultivar TMG113-RR, durante o armazenamento, utilizando imagens de raios x e testes de potencial fisiológico. Revista Brasileira de Sementes, Londrina, v. 32, n. 3, p. 123-133, set. 2010.

GONÇALVES, J. V. S. et al. Caracterização física e avaliação da pré-embebição na germinação de sementes de sucupira-preta (Bowdichia virgilioides Kunth). Cerne, Lavras, v. 14, n. 4, p. 330-334, out. 2008.

IGATHINATHANE, C.; PORDESIMO, L. O.; BATCHELOR, W. D. Major orthogonal dimensions measurement of food grains by machine vision using ImageJ. Food Research International, Barking, v. 42, p. 76-84, jan. 2009.

INTERNATIONAL SEED TESTING ASSOCIATION. International rules for seed testing. Zurich: ISTA, 2004. 180 p.

LIMA, L. K. S. et al. Utilização de técnicas na avaliação de sementes por imagem ACSA. Agropecuária Científica no Semi-Árido, Campus de Patos, v. 9, n. 3, p. 1-6, jul. 2013.

LIU, W. et al. Association of seed coat color with seed water uptake, germination, and seed components in guar (Cyamopsis tetragonoloba (L.) Taub). Journal of Arid Environment, [s. 1.], v. 70, p. 29-38, jul. 2007. LOPES, J. C. et al. Germinação de sementes de espécies florestais de Caesalpinea férrea Mart. ExTul. Var. leiostachya Benth., Cassia grandis L. e Samanea saman Merrill, após tratamento para superar a dormência. Revista Brasileira de Sementes, Londrina, v. 20, n. 1, p. 80-86, 1998.

LORENZI, H. Árvores brasileiras: manual de identificação e cultivo de plantas arbóreas nativas do Brasil. 5. ed. Nova Odessa: Instituto Plantarum, 2008. 384 p.

MAGUIRE, J. D. Speed of germination aid in selection and evaluation for seedling emergence and vigor. Crop Science, Madison, v. 2, n. 2, p. 176-177, mar. 1962.

MASETTO, T. E. et al. Qualidade fisiológica e sanitária de sementes de crambe produzidas no estado de mato grosso do sul. Revista Brasileira Oleaginosas e Fibrosas, Campina Grande, v. 13, n. 3, p. 107-113, 
2009.

MASETTO, T. E.; FARIA, J. M. R.; QUEIROZ, S. E. E. Avaliação da qualidade de sementes de cedro (Cedrela fissilis - meliaceae) pelo teste de raios x. Ciência Agrotecnologica, Lavras, v. 32, n. 6, p. 17081712, nov. 2008.

MERTZ, L. M. et al. Diferenças estruturais entre tegumentos de sementes de soja com permeabilidade contrastante. Revista Brasileira de Sementes, Londrina, v. 31, n. 1, p. 23-29, 2009.

PEREIRA, V. J. et al. Eficiência dos tratamentos para a superação ou quebra de dormência de sementes de Fabaceae. Revista de Ciências Agrárias, Recife, v. 2, n. 37, p. 187-197, jun. 2014.

RODRIGUES, A. P. D. C. et al. Tratamentos para superar a dormência de sementes de Acacia mangium Willd. Acta Science Agronomy, Maringá, v. 30, n. 2, p. 279-283, 2008.

ROSA-MAGRI, M. M.; MENEGHIN, S. P. Avaliação das características germinativas da espécie arbórea sucupira-preta (Bowdichia virgilioides Kunth - Fabaceae). Bioikos, Campinas, v. 28, n. 1, p. 3-10, jan. 2014. SILVA JÚNIOR, M. C. (Org). 100 Árvores do Cerrado: guia de campo. Brasília: Rede de sementes do Cerrado, 2005. $278 \mathrm{p}$.

SILVA, P. A. et al. Análise fisiológica e ultra-estrutural durante o desenvolvimento e a secagem de sementes de soja. Revista Brasileira de Sementes, Londrina, v. 29, n. 2, p. 15-22, 2007.

SMIDERLE, O. J.; MOURÃO JÚNIOR, M.; SOUSA, R. C. P. Tratamentos pré- germinativos em sementes de Acácia. Revista Brasileira de Sementes, Londrina, v. 27, n. 1, p. 78-85, 2005.

SMIDERLE, O. J.; SCHWENGBER, L. A. M. Superação da dormência em sementes de paricarana (Bowdichia virgilioides Kunth.). Revista Brasileira de Sementes, Londrina, v. 33, n. 3, p. 407-414, 2011. SMIDERLE, O. J.; SOUSA, R. C. P. Dormência em sementes de Paricarana (Bowdichia virgilioides kunth - FABACEAE - PAPILIONIDAE). Revista Brasileira de Sementes, Londrina, v. 25, n. 1, p. 72-75, dez. 2003.

SOUZA, L. A. et al. Uso de raios-x na avaliação da qualidade de sementes de Platypodium elegans Vog, Revista Ciência Agronomica, Fortaleza, v. 39, n. 2, p. 343-347, abr. 2008.

TONETTI, L. O. A. O.; DAVID, A. C.; SILVA, E. A. A. Qualidade física e fisiológica de sementes de Eremanthus erythropappus (DC.) Mac. Revista Brasileira de Sementes, Londrina v. 28, n. 1, p. 114-121, 2006.

VENORA, G. et al. Identification of Italian landraces of bean (Phaseolus vulgaris L.) using an image analysis system. Scientia Horticulturae, Amsterdam, v. 121, p. 10-418, ago. 2009.

VENORA, G. et al. Identification of Sicilian landraces and Canadian cultivars of lentil using an image analysis system. Food Research International, Barking, v. 40, p. 161-166, jan. 2007. 